\title{
Progress and problems of gender equality in Japanese academics and geosciences
}

\author{
Rie S. Hori ${ }^{1,2,3}$ \\ ${ }^{1}$ Women's Future Development Center of Ehime University, Matsuyama, 790-8577, Japan \\ ${ }^{2}$ Department of Earth Sciences, Ehime University, Matsuyama, 790-8577, Japan \\ ${ }^{3}$ Gender Equality Committee Chair, the Geological Society of Japan, Tokyo, 101-0032, Japan
}

Correspondence: Rie S. Hori (shori@sci.ehime-u.ac.jp, hori.rie.mm@ehime-u.ac.jp)

Received: 26 March 2020 - Revised: 5 July 2020 - Accepted: 8 July 2020 - Published: 4 September 2020

\begin{abstract}
In its gender equality status, Japan lags behind the European Union (EU) and other Organisation for Economic Co-operation and Development (OECD) countries. Only $16.7 \%$ of academic staff in national universities are women. Although there has been a slow improvement during the last 45 years, the percentage of female staff remains particularly low in the STEM (science, technology, engineering, and mathematics) fields. In 2018, female stuff accounted for only $12.3 \%$ in agriculture, $8.7 \%$ in science, and $6.2 \%$ in engineering. The number of female graduate students and the number of female members of the Japanese geoscience societies have been steadily increasing since the 1998 campaign that increased the total number of graduate school places. However, low representation of females in academic job positions, as well as among the recipients of academic awards, suggests that a strong unconscious bias against women still exists in Japan. Continuing public attention to these issues is essential for the improvement of the situation.
\end{abstract}

\section{Introduction}

According to the global gender equality rankings by the World Economic Forum (2020), the Gender Gap Index (GGI) rank of Japan has been below 100 during the last 8 years. The GGI is defined by female contributions to the following four fields: (1) economic participation and opportunity, (2) educational attainment, (3) health and survival, and (4) political empowerment. Every 4 years, Japan's ranking has been slipping by 10 points and finally reached the 121 st position in 2019 due to distinctive declines in fields (1) and (4). In 2011, the Japanese government released the Promotion of Positive
Action program with a target to have $30 \%$ female participation in the workplace including academia by 2020 . However, this goal has not been met as yet, and the major trend of the Japanese GGI has continued to decrease since 2011 (Fig. 1). Based on the 15th survey by the Japan Association of National Universities, which includes most of the geoscience departments in Japan, only $4 \%$ of national universities have achieved a $>30 \%$ female ratio of total academic staff. The average ratio increased slightly from $13.0 \%$ (2011) to $16.7 \%$ (2018). The change is quite slow, and the rate of change is not increasing over time. In the STEM (science, technology, engineering, and mathematics) fields, female staff ratios were at $12.3 \%$ (agriculture), $8.7 \%$ (science), and $6.2 \%$ (engineering) in 2018. The percentage of undergraduate female students in science has gradually decreased during these 10 years from ca. $28 \%$ to $25 \%$ in total, while the number of women in $\mathrm{PhD}$ studies increased as a result of several empowerment programs. There have been numerous discussions about the cause of the slow improvement and low values of female ratios in the STEM fields in Japan. According to statistical data by Japan Inter-Society Liaison Association Committee for Promoting Equal Participation of Men and Women in Science and Engineering (EPMEWSE, 2017; Sato et al., 2018), the main reason for this seems to be unconscious bias. A recent incident with gender control during enrollment at a school of medicine provides an example of unconscious bias. In 2018, at least 10 Japanese universities controlled gender ratios of admitted students by artificially decreasing the evaluation points of female examinees because they considered female doctors more likely to leave the job than males, for which there is no statistical evidence. 




Figure 1. Gender Gap Index ranking of Japan from 2011 to 2019. Data from the World Economic Forum.

In this paper, we present information on gender status and problems in Japanese academia, including geoscience societies, and discuss ways for improvement.

\section{Japanese female researchers}

Based on fact sheet no. 55 of the UNESCO Institute for Statistics (2019), the participation of female researchers in Japan is among the lowest in the Asia and Pacific region. In Asia, participation values range from $7.8 \%$ to $75.6 \%$ with an average of $29.3 \%$. For Japan, this value is $16.6 \%$, the lowest among the values of other Organisation for Economic Co-operation and Development (OECD) members and partners (Fig. 2). According to the Summary of Results (2019) of Research and Development by the Statistics Bureau of Japan, currently there are 874800 researchers working in academia and industry; $16.6 \%$ of them (155000 individuals) are female. Female participation in research has increased only slightly during the last 10 years, from $13.6 \%$ in 2009 to $16.6 \%$ in 2018 (Fig. 3). However, among new researchers recruited in 2017 and 2018, the number of women reached $28.5 \%$ and $29.9 \%$, respectively. About $30 \%$ of new researchers are women, and $90 \%$ of them are STEM researchers. If this trend continues, we can hope that the work environment will improve for female scientists in the future.

\subsection{Female status in universities in Japan}

There are 86 national universities, or national cooperation universities, in Japan. The majority of the geosciences departments belong to these national universities. Every year, the Japan Association of the National Universities surveys and reports on its gender equality statistics. The data show certain progress in female participation in academic life. The percentage of women in academic staff increased from $2.5 \%$ in 1972 to $16.7 \%$ in 2018 (Fig. 4). The increase was gradual, except for a single stepwise increase of $1.9 \%$, from $9.6 \%$ to $11.5 \%$, within 1 year from 2006 to 2007. In 1972, the number of female students was at $20 \%$ for undergraduates and

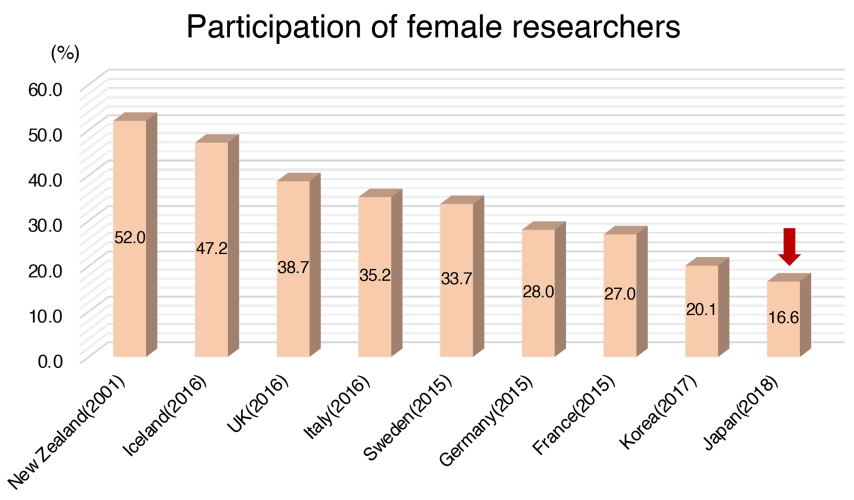

Figure 2. Percentage of female researchers. Data from fact sheet no. 55 of the UNESCO Institute for Statistics (2019) except for Japan. Data for Japan are taken from the Summary of Results (2019) of Research and Development by the Statistics Bureau of Japan.

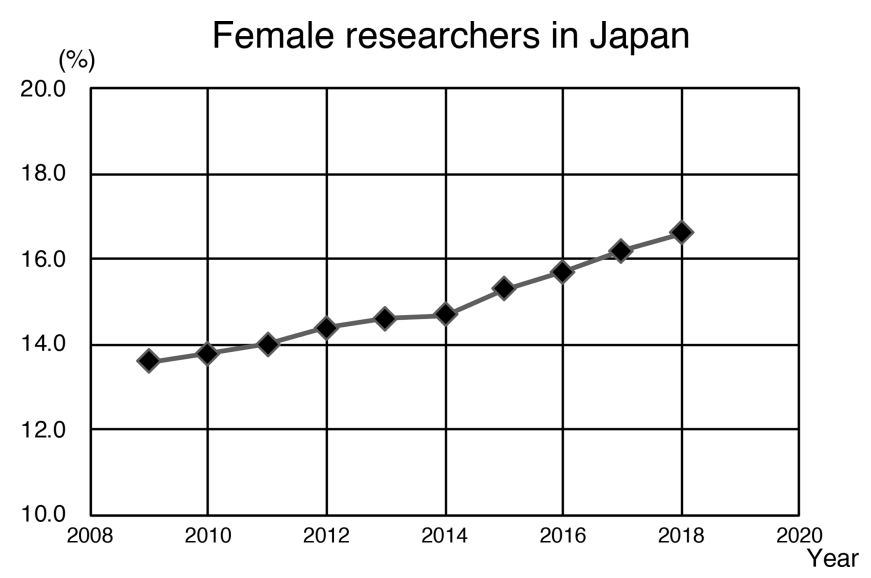

Figure 3. Percentage values of female researchers in Japan from 2009 to 2018 as reported in the Summary of Results (2019) of Research and Development by the Statistics Bureau of Japan.

about $5 \%$ for PhD students. The number of female undergraduates increased gradually, reaching a plateau at $30 \%-$ $38 \%$ in the 2000 s. The number of PhD students rose slowly to $15 \%$ by 1998 , then the growth in numbers accelerated. The difference in undergraduate and $\mathrm{PhD}$ trends is likely related to the government policy aimed at the advancement and diversification of graduate school education and research. From 1998, many national universities increased admittance to graduate school programs, which led to an increase in total student numbers almost of 2.5 times. Thus, the number of students in graduate programs at Japanese universities increased from 69688 in 1985 to 239460 in 2005 . The increase may have provided a good opportunity for female students aiming to pursue higher education.

Figure 5 shows temporal changes in the percentages of female staff in different job positions in Japanese national universities. Before 2006, academic job positions included assistant, lecturer, associate professor, and professor in as- 


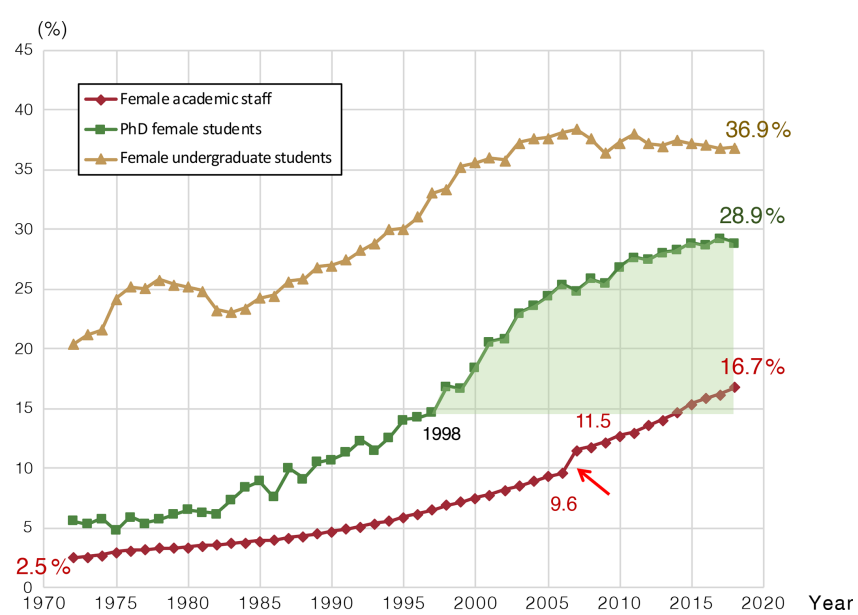

Figure 4. Percentage of women in national universities in Japan from 1972 to 2018. Data for 2015, 2017, and 2018 are taken from reports of the Japan Association of National Universities. A red arrow shows the increasing female academic ratio that occurred in 2007.

cending hierarchical order. An assistant position does not permit lecturing; therefore, assistants were not included in academic number counts. In 2007, the position of assistant professor was subdivided into assistant and research associate. The duty of an assistant is supporting academic activities in universities, while the position of research associate permits teaching. Figure 5 demonstrates that the number of females in lower academic positions is always higher than those at the assistant professor and professor levels. In 2017, $22.2 \%$ of research associates, $16.3 \%$ of associate professors, and $9.5 \%$ of professors in national universities were female. During the last 20 years, the gap between the numbers of female associate professors and professors has increased. The leaking pipe problem exists in Japanese academia and has recently become worse. This problem needs to be acknowledged and addressed. Although Japanese national universities have significantly lower overall female staff participation compared to the European Union (EU) countries, positive progress is evident in the increasing numbers. In 1972, the percentage of female associate professors and professors was at $3.0 \%$ and $1.2 \%$, respectively. By 2018 , those numbers rose to $16.7 \%$ and $10.3 \%$. This is considered a large improvement for Japanese society.

In 2006, the Japanese government introduced an action plan entitled Supporting Activities for Female Researchers - Funds for Promoting Science and Technology of the Ministry of Education, Culture, Sports, Science and Technology (MEXT, 2006). It seems that the positive shift in female participation between 2006 and 2007 (see Fig. 4) occurred due to this government action. However, if we focus on the temporal changes in the female percentage in each job category, an alternative explanation can be offered. Only since the 2007 change in the academic classification system has the number of research assistant positions been included in the total count of academic staff positions. It is possible that the positive shift from 2006 to 2007 values in Fig. 5 is mostly due to the inclusion of female research associates in the count.

Ehime University is a representative example of the Japanese national cooperation universities in the local districts of Japan. Ehime University has similar faculties and shows an average value $(17.6 \%)$ of the female academic staff ratio among national universities. Figure 6 shows female staff percentages of all faculties at Ehime University, as well as the female percentage of each job position. The female percentage values clearly decrease at STEM faculties and are also decreasing from assistant professor and lecturer to professor positions. This suggests that a certain unconscious bias exists in promotion and recruitment processes, even though the university has always declared that "Ehime University hires its employees in compliance with the spirit of striving for gender-equal society, and promotes various programs to develop diversity in the research environment".

\subsection{Female students at national universities}

In $2018,53.3 \%$ of high school graduates enrolled in universities in Japan, and $49.1 \%$ of those enrolled were female. When 2-year colleges are included, female enrollments increase to $57.7 \%$. These data suggest that females are more likely to pursue higher education opportunities than males (data from the MEXT Japan report, 2018). The average undergraduate female student percentage in Japanese universities is $45.1 \%$. The percentages of female students in the STEM fields at the national universities show an increasing trend in faculties of agriculture and engineering (see Fig. 7a), while faculties of science and faculties of education saw a decrease in numbers (Fig. 7b). Faculties of agriculture report the highest percentage of female students at $>40 \%$. In the engineering field, the female student numbers, although gradually increasing, are still quite low at $11 \%-14 \%$. Ehime University shows similar increasing and decreasing trends in these faculties; however, there are much lower percentages of female students in faculties of engineering and science. A clear gender bias is observed between the female ratios of students and professors at national universities. Ehime University's example is shown in Fig. 8. Female student percentages in most faculties are higher than female professor percentages. This suggests that there is a certain bias in the recruitment processes of academic staff at the university. The Department of Earth Sciences (Geoscience) shows better statistics compared to others in the STEM fields (shown by a star in Fig. 8). This relative improvement is probably due to awareness of gender issues in the department and the high percentage of female professors.

In Japan, there are many STEM education activities available for female high school and junior high school as well as elementary school students. These activities and programs aim to help women choose their future careers unconstrained 


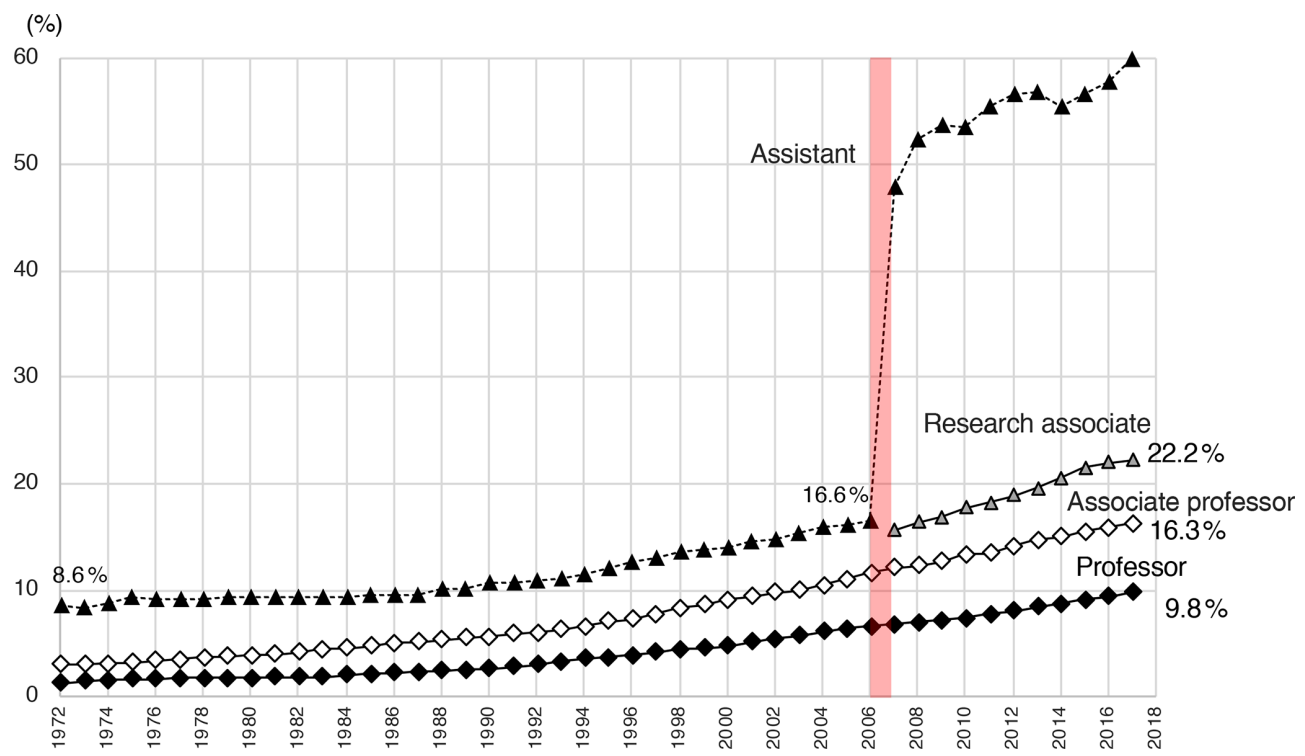

Figure 5. Job position and percentage of female staff in national universities in Japan from 1972 to 2018. Data for 2015, 2017, and 2018 are taken from the reports of the Japan Association of National Universities. The shaded area highlights a big change from 2006 to 2007.

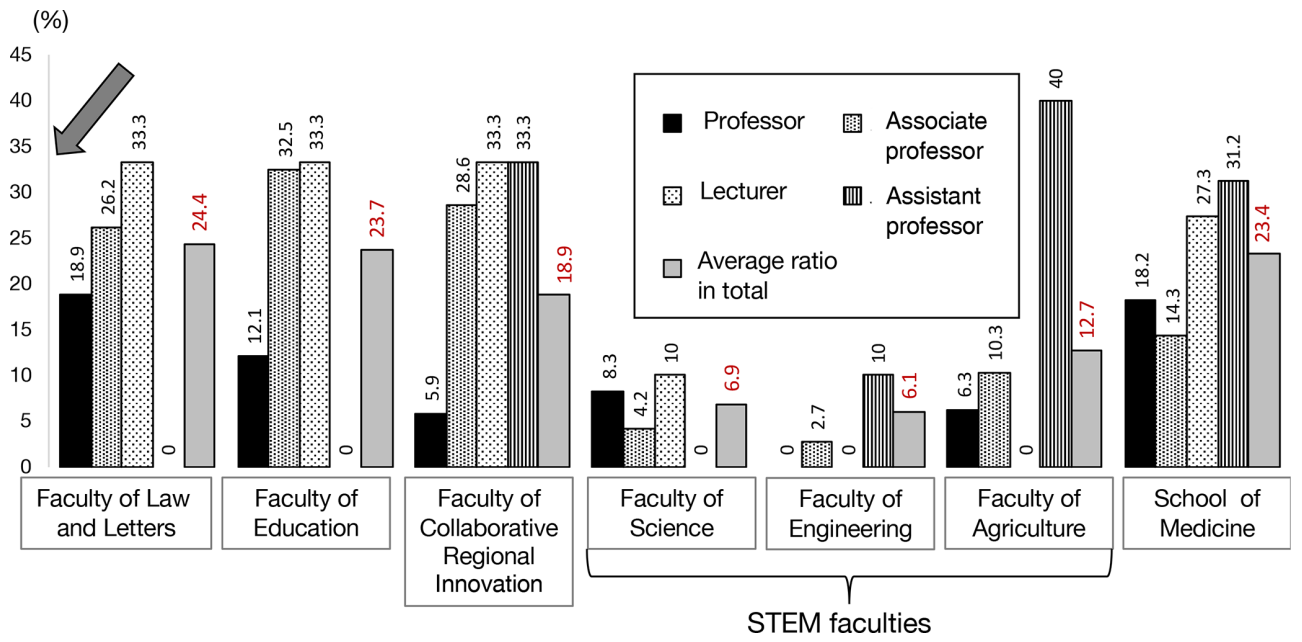

Figure 6. Job position and percentage of female staff in faculties at Ehime University, Japan. From data for May 2018.

by social bias, such as parents' wishes or the lack of familiar role models. These programs include, for example, RicoChallenge (a science and technology challenge), STEM Girls Ambassadors (supported by the Cabinet Office of Japan), and various JST (Japan Science and Technology Agency) Rikejo development programs.

Ehime University has been participating in the JST program since 2012. In 2016-2017, the Women's Future Development Center at Ehime University conducted a Rikejo development program for junior high and high school students that was supported by JST funds. A total of 366 female high school and junior high school students and 93 parents took part in the "science princess project" at Ehime University during these 2 years. The program mainly consisted of three types of activities: (1) visiting laboratories of STEM faculties, (2) visiting companies empowering their female technical staff, and (3) attending presentations by female students who are currently studying in the STEM fields. These events provided an opportunity to meet with good female role models who are currently studying or working in the STEM fields. After these events, we received a positive response from the participants. More than $85 \%$ of female students who attended the program indicated the following: "I have a strong desire to study science and technology" or "I am going to study science and technology". The parents who attended the program with their children responded as follows: "We understand well the opportunities in the STEM research and employment" (91\%) and "We can give some 



55 $200420052006200720082009201020112012 \quad 2013 \quad 2014 \quad 2015 \quad 2016 \quad 2017$

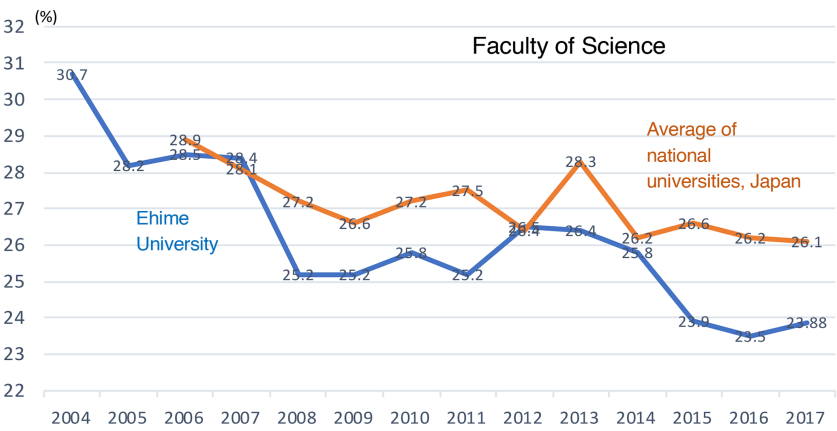

Figure 7. Temporal changes in female student numbers at national universities, Japan. Orange line: average value. Blue line: value of Ehime University for the cases of four faculties (agriculture, engineering, education, and science).

suggestions to our children about the future study and work after participating in the program" $(80 \%)$.

These activities, which have been continuing for more than 10 years, led to some success in increasing the percentages of female students in graduate school, as well as increasing enrollment into undergraduate courses in engineering and agriculture. However, a decreasing enrollment trend in the Faculty of Science during the same time is worrying and needs to be addressed.

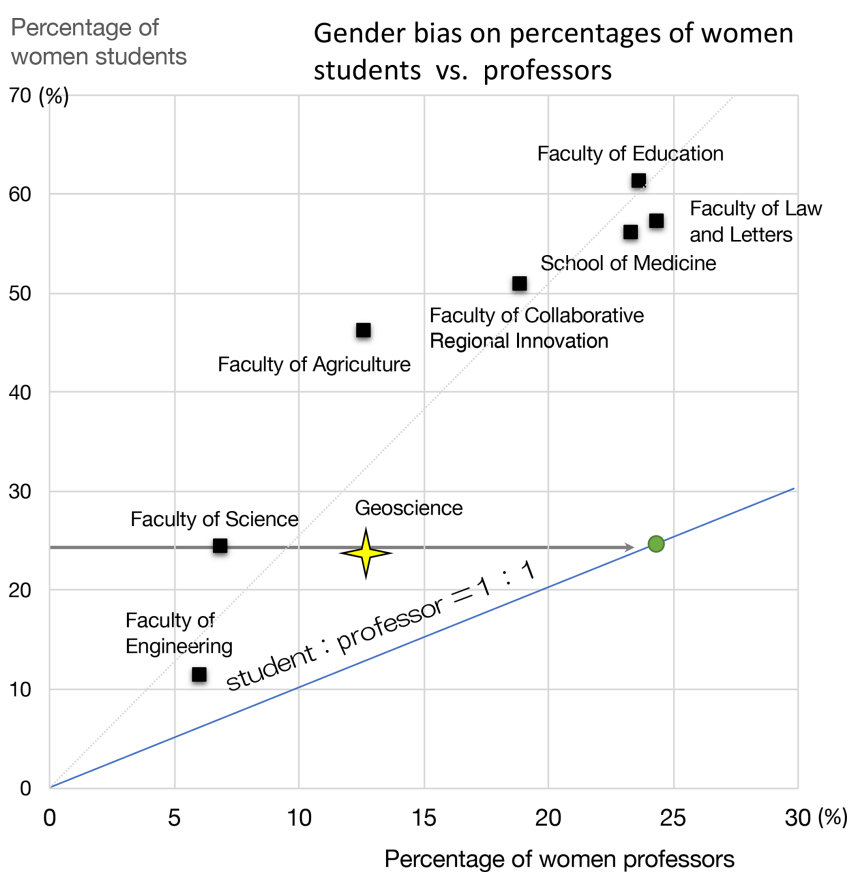

Figure 8. A graph of percentages of women students vs. professors in seven faculties and departments at Ehime University, Japan. There is a large gap between student and professor ratios in general.

In 2018, a MEXT-supported network for sharing information on practices and activities promoting gender equality was established between universities, public and private institutions, and public organizations involved in gender equality research (OPENeD) (see https://www.opened.network/ english/about-this-site/, last access: 30 June 2020 in English). It is hoped that this network will help to improve the Japanese statistics on gender issues, which are currently lagging behind other OECD countries.

\section{Problems of gender equality in Japanese academics and geosciences}

The Japan Geoscience Union (JpGU), established in 2005, is one of the largest academic organizations related to the geosciences. It has more than 9000 individual members and 50 society members (2016 data). About $20 \%$ of JpGU members are women. The Geological Society of Japan (JGS), established in 1893, has a much longer history. The JGS has 3502 members, including 369 female members (2019 data). The changes in the JGS membership from 1990 to 2019 are shown in Fig. 9. The total number of members peaked in 2000 at 5308 and has decreased since to the current number of 3502 members. The number of female members was slowly increasing during 1990 and 1996, then increased stepwise (from 260 to 375) in 1998. This stepwise increase corresponds to the increasing number of graduate school students in Japan. Since 1998, the number of female members has 


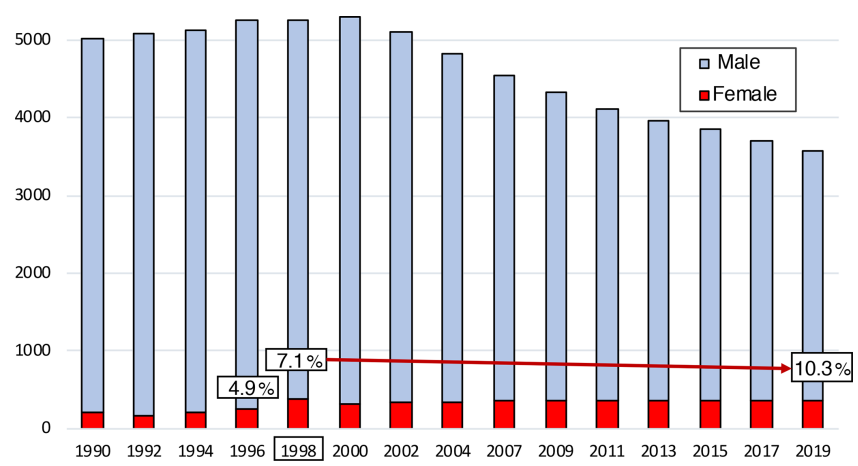

Figure 9. Female and total membership in the Geological Society of Japan since 1990.

stayed constant at about 370 , while the number of male members has decreased. Consequently, the relative abundance of female members has increased from $7.1 \%$ in 1998 to $10.1 \%$ in 2019.

As yet, there has been no female president of either the JpGU or JGS. Among the 437 recipients of JGS awards, only $19(4.3 \%)$ are women (Fig. 10). The JGS also grants honorary member awards. There have been no females among the 169 recipients of the honorary member awards during the 127-year-long history of the society (Fig. 11). The JpGU has a similar honorary member award, called a JpGU fellow. There were only three females among the total of $106 \mathrm{JpGU}$ fellows awarded between 2014 and 2019 (Fig. 12). While better than JGS statistics, the number of female award recipients is still low (2.8\%) compared to the total female membership (ca. $20 \%$ ).

The promotion of gender equality in the geosciences by the JGS started some time ago. A gender equality committee organized in 1995 held meetings and excursions for female researchers and students during the annual conference. Since 1998, the committee has been providing childcare services at the conference venue or nearby for female members who would like to attend the annual meeting with kids. The precursor organization of the JpGU, called Godo-Meeting, was established in 1990. During its 1998 meeting, female researchers petitioned to establish the first nursery room at the conference venue (National Olympics Memorial Youth Center, Tokyo) for participants with kids; this service has been continuing since then. The services by both the JGS and JpGU help their young members, male as well as female, who need to take care of their children while continuing their academic careers without breaks due to family and life responsibilities.

The formal action on gender equality by the JpGU started in 2005 when the first symposium on gender equality in the Earth sciences was held. A gender committee was organized and operated from 2007 to 2015. Since then, the committee has changed its name to the Committee for Diversity Man-

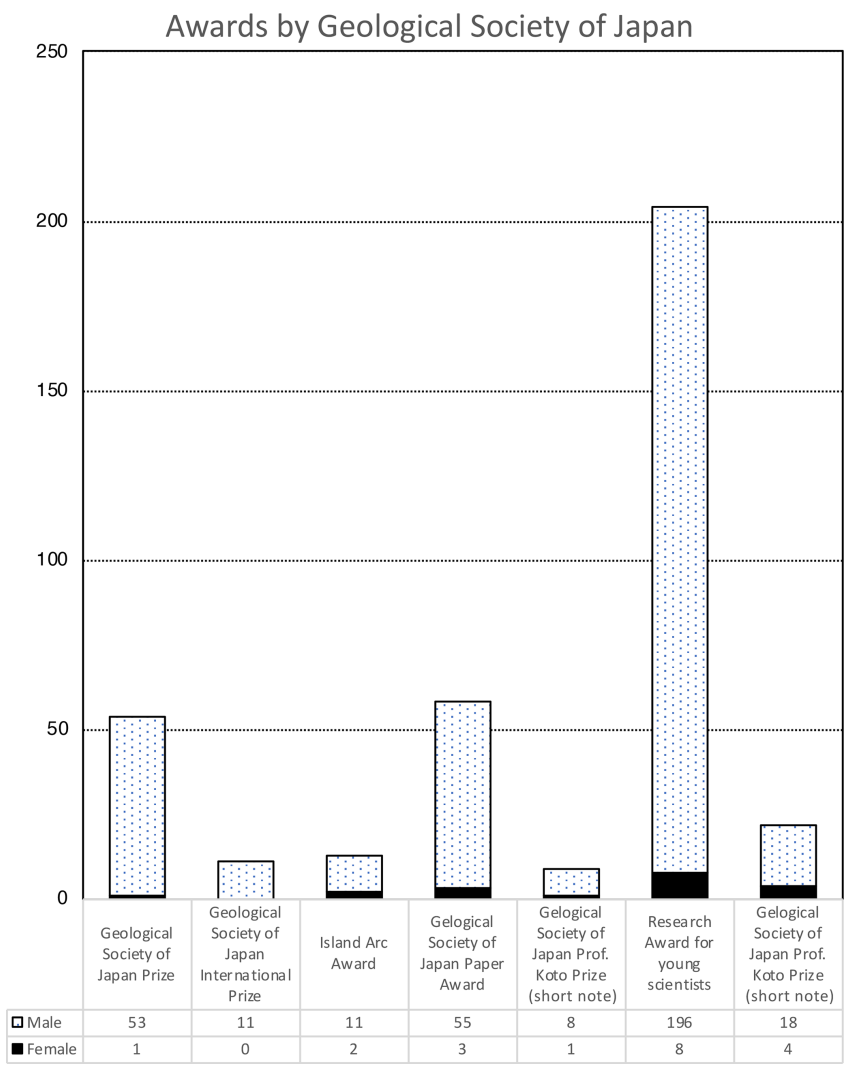

Figure 10. Male and female recipients of awards from the Geological Society of Japan.

agement and Talent Pool in recognition of the wider range of diversity needs of the members.

\section{Discussion and conclusion}

We have recognized the following three main problems concerning gender issues in Japan.

1. The improvements in gender representation in Japanese academia are very slow.

2. The number of undergraduate students in the sciences is decreasing.

3. A certain bias exists against women in terms of recruitment and/or promotion among research and academic fields.

As mentioned above and as many scientists have already pointed out (e.g., Homma et al., 2013), gender equality in Japan is improving very slowly, and in some cases it may even experience setbacks (Fig. 1). Although there are many programs directed at improving gender equality in Japan, it seems that the leaking pipeline is worsening. In addition, the number of undergraduate students in science is decreasing, 


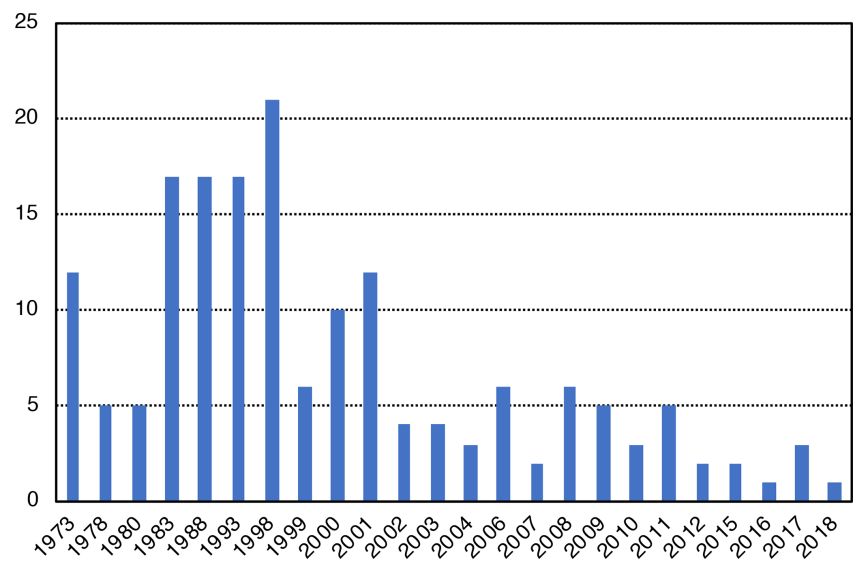

Figure 11. Honorary members of the Geological Society of Japan from 1973 to 2018 . There are no females among the 169 honorary members.

thus limiting the potential for future improvement. According to the White Paper on Gender Equality (2019) by the Gender Equality Bureau Cabinet Office, Japan, $33.8 \%$ of girls who have female science teachers indicated the following: "I am a science-type or rather science-type", which is clearly a higher percentage than those who have male science teachers $(22.5 \%)$ based on a survey of junior high school students $(n=1000)$. It is suggested that the presence of role models is significantly important for girls to generate interest in STEM fields. There are many similar results and surveys documented on a large scale and domestic scale, as well as in other countries (e.g., Microsoft Report, 2018). We need to provide much better and varied role models for high school and junior high school students.

The most effective way to speed up the slow improvement process is considered to be increasing the total number of graduate school places, similar to the 1998 increase, as well as increasing the total female academic staff, similar to the change between 2006 and 2007. Increasing the total student numbers in universities will provide more opportunities for female students and researchers. However, to stop the leaking career pipeline from $\mathrm{PhD}$ students to academic staff, from research assistant to associate professor positions, and from associate professor to professor, we need to do more and to be aware of the existence of the unconscious biases against women. According to Sato et al. (2018), ca. $40 \%$ males and $50 \%$ females answered the question of why females are fewer in high job positions (e.g., PI or professor) than males; it is believed to be because females can more easily leave the job than males. This is not true. The leaving ratio of female researchers is $7.3 \%$, which is similar to $5.9 \%$ of male (Sato et al., 2018). In addition, according to data from the Survey Report (2013) of the 3rd Large-Scale Survey of Actual Conditions of Gender Equality in Scientific and Technological Professions by the Japan Inter-Society Liaison Association Committee for Promoting Equal Partici-

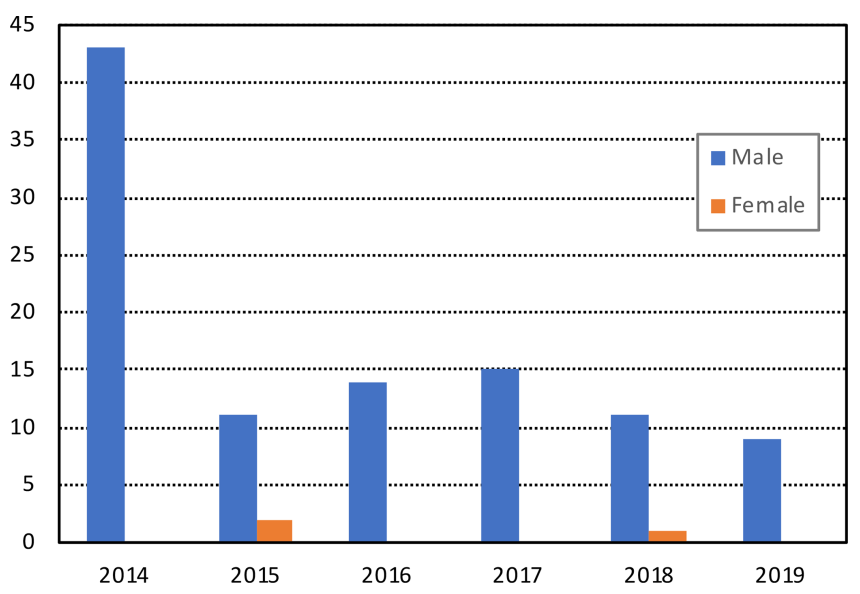

Figure 12. The JpGU fellow members from 2014 to 2019. There are three female members among the total of 106 fellows.

pation of Men and Women in Science and Engineering (EPMEWSE), there are differences in career goals between female and male researchers. Among male researchers, $38.5 \%$ aim to become a leader of an academic or research institution lab (PI), while only $24.5 \%$ of female scientists aim at that. The major career goal of female researchers is to work in an academic or research institution lab, not to become a PI (EPMEWSE Survey Report English, 2017). In these cases, we recognized a certain unconscious bias in their career images. This should be taken into consideration during recruitment processes. To start with, the number of female recruitment committee members should be systematically increased to $30 \%$, as suggested by the Gender Equality Bureau Cabinet Office of Japan (2011). Then, the committee members must recognize unconscious biases and overcome them.

Good bias avoidance training systems are needed for the Japanese academic field. The concept of unconscious bias has been introduced by Prof. Hisako Ohtsubo from the Nihon University and EPMEWSE (for details, see Sato et al., 2018, and https://www.djrenrakukai.org/doc_pdf/2017/ UnconsciousBias_leaflet.pdf, last access: 31 January 2019). Prof. Ohtsubo has given numerous talks on the unconscious gender bias in Japanese universities and academia. We need to acknowledge the existence of the bias and to positively discriminate in favor of female candidates during hiring, deciding on pay scale or other benefits, and in recognition and award selection processes.

When surveying the views of young Japanese researchers on gender issues and work-life balance, we found that most researches have not given enough thought to these questions. This is evident during society meetings. Compared to the EU and other countries, smaller audiences, particularly of male or young researchers, attend the gender and diversity sessions of Japanese society conferences because of the lack of interest in these issues. $\mathrm{PhD}$ graduates in Japan struggle to find a stable job these days. Almost $24 \%$ of the researchers, 
the majority of JpGU members, are taking up limited-term jobs (Sakanoi, 2015; research about gender and young career paths by JpGU). They are busy looking for better permanent jobs or trying to improve their CV. However, these job-hunting difficulties are similar to those of $\mathrm{PhD}$ graduates in the USA, the EU, and other countries. In the Japanese education system, there seems to be a general lack of awareness and a paucity of information on better society organization with gender equality and inclusion. Professors and institutions of higher education in Japan should teach not only science and technical skills but also cover issues related to diversity, professional development, and geoethics. The awareness is an important first step in improving the "lagging behind in gender equality" status of Japan. Maintaining continued public attention to the problem is also essential.

Data availability. Data supplied by the Geological Society of Japan on membership and honors demographics are used, which are accessible here: http://www.geosociety.jp/outline/ content0114.html, http://geosociety2.sakura.ne.jp/en/jgs-awards, and http://www.geosociety.jp/uploads/fckeditor//engineer/woman/ 2000-2007.jpg (last access: 1 March 2020). JpGU fellowship source data are accessible at http://www.jpgu.org/jpgufellow/ (last access: 1 March 2020), and student- and staffsupplied data for Ehime University are accessible here: http://kiteisv.office.ehime-u.ac.jp/iddesk/ (in Japanese, last access: 30 June 2020). The other data used in the figures are open to the public; access information is described in the text and references.

Competing interests. The author declares that there is no conflict of interest.

Special issue statement. This article is part of the special issue "Diversity and equality in the geosciences (EGU2019 EOS6.1 \& US4, AGU2018 ED41B, JpGU2019 U-02)". It is a result of the JpGU Annual Meeting 2019, Chiba, Japan, 26-30 May 2019.

Acknowledgements. The author gratefully acknowledges Chiaki Oguchi, the chair of the Committee for Diversity Management and Talent Pool of the JpGU, and the Geological Society of Japan office for providing information on gender statistics, as well as Claudia Alves de Jesus-Rydin for providing an opportunity and encouragement to submit this article to the special issue, Alexandra Abrajevitch, and the reviewers for their help in writing and improving this paper.

Review statement. This paper was edited by Claudia Jesus-Rydin and reviewed by Adina Paytan and one anonymous referee.

\section{References}

Cabinet Office, Government of Japan: promotion of "Positive Action" - Aiming to arraign the target of " $30 \%$ by 2020 " - from the "White Paper on Gender Equality 2011", 2011, available at: http://www.gender.go.jp/english_contents/pdf/ewp2011.pdf (last access date: 15 January 2020), 2011.

EPMEWSE (The Japan Inter-Society Liaison Association Committee for Promoting Equal Participation of Men and Women in Science and Engineering): Survey Report (2013) of the 3rd Large-Scale Survey of Actual Conditions of Gender Equality in Scientific and Technological Professions, 2013, available at: https://www.djrenrakukai.org/doc_pdf/2013/3rd_enq/ 3rd_enq_report130918.pdf, https://www.djrenrakukai.org/doc_ pdf/3rd_enq_report_en.pdf (last access date: 3 March 2020), 2013.

EPMEWSE: Survey Report (2017) of the 4th Large-Scale Survey of Actual Conditions of Gender Equality in Scientific and Technological Professions, available at: https://www.djrenrakukai. org/doc_pdf/2017/4th_enq/4th_enq_survey_report_en_v2.pdf (last access date: 3 March 2020), 2017.

EPMEWSE: Understanding Unconscious Bias, available at: https://www.djrenrakukai.org/doc_pdf/2017/UnconsciousBias_ leaflet.pdf, https://www.djrenrakukai.org/doc_pdf/2019/ UnconsciousBias_leaflet_eng.pdf (last access date: 3 March 2020), 2017.

Gender Equality Bureau, Cabinet Office: The White Paper on Gender Equality, available at: http://www.gender.go.jp/ english_contents/about_danjo/whitepaper/pdf/ewp2019.pdf,

http://www.gender.go.jp/about_danjo/whitepaper/r01/ zentai/html/zuhyo/zuhyo01-00-15.html (last access date: 30 June 2020), 2019.

Homma, K. M., Motohashi, R., and Ohtsubo, H.: Japan's Lagging Gender Equality, Science, 340, 428-430, https://doi.org/10.1126/science.340.6131.428-b, 2013.

JANU (The Japan Association of National Universities): Gender equality committee Report No. 12, available at: https:// www.janu.jp/gender/201602houkoku_01.pdf (last access date: 24 February 2020), 2015.

JANU: Gender equality committee Report No. 14, available at: https://www.janu.jp/gender/201801houkoku_01.pdf (last access date: 24 February 2020), 2017.

JANU: Gender equality committee Report No. 15, available at: https://www.janu.jp/gender/201901houkoku_01.pdf (last access date: 24 February 2020), 2018.

MEXT (The Ministry of Education, Culture, Sports, Science and Technology): An action program "Supporting Activities for Female Researchers", available at: https://www.jst.go.jp/ shincho/josei_shien/en/program/index.html, https://www.jst.go. jp/shincho/josei_shien/en/index.html (last access date: 15 December 2019), 2006.

MEXT: Statistics, Japan report 2018, available at: https://www. mext.go.jp/en/publication/statistics/index.htm (last access date: 3 March 2020), 2018.

Microsoft Report: How role models are changing the face of STEM in Europe, available at: https://3er1viui9wo30pkxh1v2nh4wwpengine.netdna-ssl.com (last access date: 30 June 2020), 2018.

OPENeD: All Nippon Diversity Network, available at: https://www. opened.network/about/platform/ (last access: 17 July 2018) in 
Japanese, https://www.opened.network/english/about-this-site/, last access: 30 June 2020.

Sakanoi, K.: Reports of JpGU career path questionnaire, JpGU O04-02, 2015.

Sato, M, Hirata-Kohno, H., Ishii, Y., Suzuki, K. CSakai, H., and Ohtsubo, H.: Overcoming Unconscious Bias in STEM, Transactions of Nihon University, School of Dentistry, 46, 33-44, 2018.
Statistics Bureau of Japan: Summary of Results (2019) of Research and Development, available at: https://www.stat.go.jp/english/ data/kagaku/1546.html (last access: 3 March 2020), 2019.

UNESCO: Women in Science. Fact sheet No. 55, the UNESCO Institute for Statistics, FS/2019/SCI/55, available at: http://uis.unesco.org/sites (last access: 3 March 2020), 2019.

World Economic Forum: Global Gender Gap Report 2020, 1371, available at: http://www3.weforum.org/docs/WEF_GGGR 2020.pdf (last access: 3 March 2020), 2020. 